\title{
Considerações Acerca da Compreensão em Leitura no Ensino Superior
}

\author{
Considerations About Reading \\ Comprehension In Undergraduation \\ Consideraciones Acerca De La Comprensión \\ En Lectura En La Enseñanza Superior
}
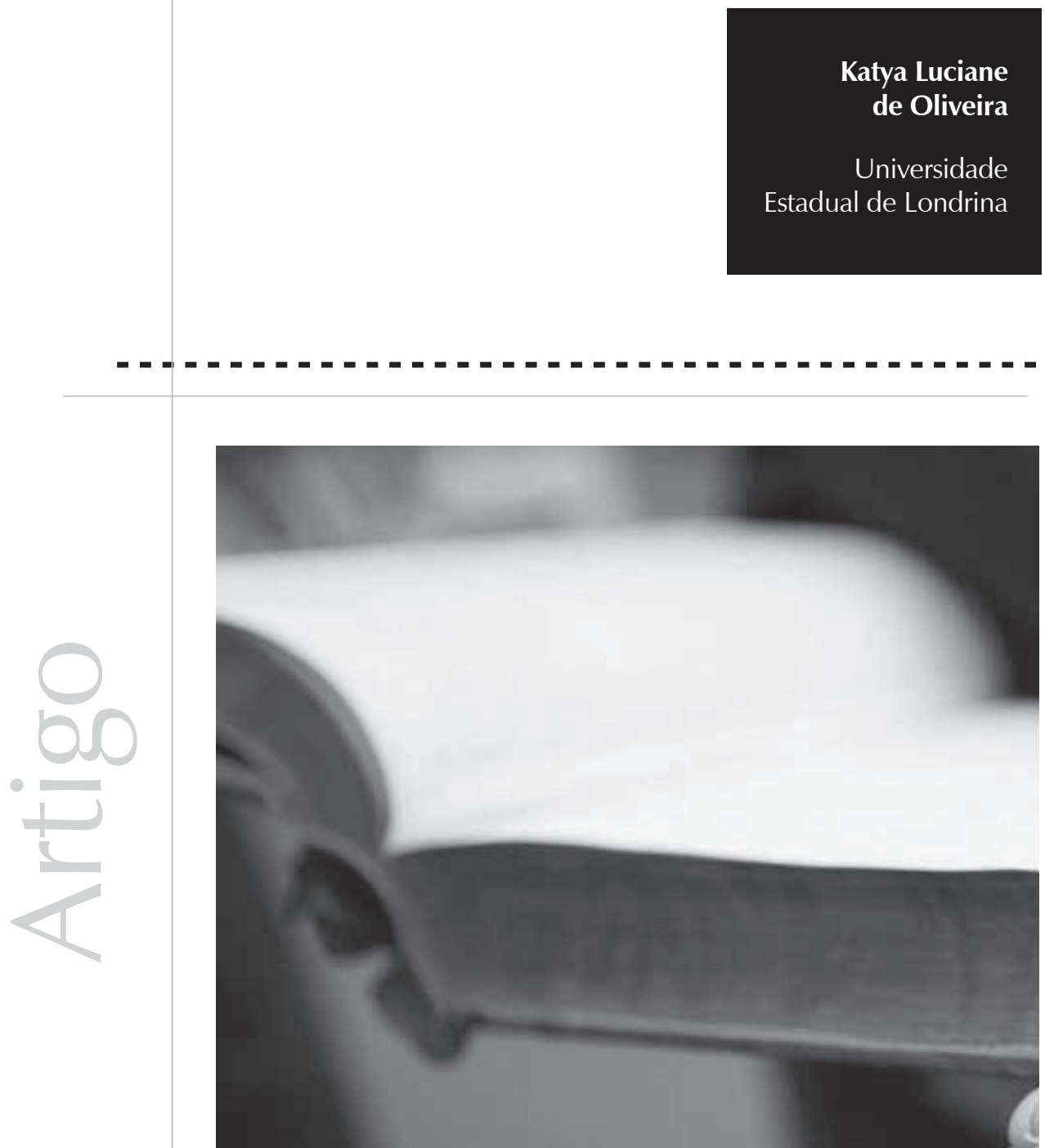
Resumo: O objetivo deste estudo foi explorar a compreensão em leitura de estudantes universitários de diferentes Estados, universidades e cursos. Participaram 1022 universitários dos cursos de Administração, Direito, Psicologia, enfermagem, odontologia, educação física e Matemática de universidades públicas e privadas dos Estados de São Paulo, Minas Gerais e Paraná. Foi utilizado um texto de 250 vocábulos, preparado segundo a técnica de Cloze, em sua versão tradicional, em que se omitem todos os quintos vocábulos do texto. A aplicação foi coletiva, e os dados, submetidos à estatística descritiva e inferencial. A habilidade de compreensão de leitura foi baixa, e houve diferença na dificuldade relacionada às classes gramaticais. Os dados são discutidos em termos de suas implicações para a área de avaliação psicoeducacional.

Palavras-chave: Leitura. Técnica de Cloze. Habilidade para leitura. Universidades. Estudantes universitários.

Abstract: The aim of this study was to explore the reading comprehension of students in different states, universities and courses. 1022 university students from Administration, Law, Psychology, Nursing, Dentistry, Physical Education e Mathematics courses from public and private universities in the states of São Paulo, Minas Gerais and Paraná participated in the study. A text of 250 words, prepared according to the Cloze technique, in its traditional version which omits all the fifth words of the text was used. The application was collective and the data were submitted to inferential and descriptive statistics. The skill of reading comprehension was low and there was no difference in difficulty related to the grammatical classes. The data were discussed in terms of their implications for the psychoeducational assessment area.

Keywords: Reading. Cloze's technique. Reading skills. Colleges. College students.

Resumen: El objetivo de este estudio fue explorar la comprensión en lectura de estudiantes universitarios de diferentes Estados, universidades y cursos. Han participado 1022 universitarios de los cursos de administración, derecho, psicología, enfermería, odontología, educación física y matemática de universidades públicas y privadas de los Estados de San Pablo, Minas Gerais y Paraná. Un texto de 250 vocablos, preparado según la técnica de Cloze en su versión tradicional, en la que se omiten todos los quintos vocablos del texto que se ha utilizado. La aplicación ha sido colectiva, y los datos han sido sometidos a la estadística descriptiva y de inferencia. La habilidad de comprensión de lectura ha sido baja y ha habido diferencia en la dificultad relacionada a las clases gramaticales. Los datos son discutidos en términos de sus implicaciones para el área de evaluación psicoeducacional.

Palabras clave: Lectura. Técnica de Cloze. Universidades. Habilidades para lectura. Estudiantes universitarios

Os Parâmetros Curriculares Nacionais de Língua Portuguesa - PCNLP (1998) enfatizam que a leitura constitui um dos principais conteúdos do currículo escolar brasileiro. Por sua vez, os Parâmetros Curriculares Nacionais - PCN/MEC (1997) assinalam que o aluno, ao concluir o ensino fundamental, deveria apresentar uma leitura proficiente, o que se manifestaria, especialmente, na compreensão do conteúdo lido. No entanto, dados do INEP (2004) evidenciam que sequer os estudantes do ensino médio demonstram o domínio dessa habilidade.

Oliveira, Boruchovitch e Santos (2009) e Silva e Witter (2009) argumentam que, diante dessa realidade, pouco se tem feito para remediar essa situação por meio de programas interventivos que possam melhorar a habilidade de leitura dos estudantes das diferentes etapas da escolarização. Portanto, é fato que, quando o estudante do ensino médio ingressa em um curso superior, carrega consigo muitas dificuldades relativas à leitura e à sua compreensão.

Esse fato fica visível quando se consideram pesquisas realizadas com alunos do ensino médio, como as de Joly, Santos e Marini (2006) e Oliveira, Cantalice e Freitas (2009), que evidenciaram que esses alunos possuem apenas uma leitura de decodificação, com pouca compreensão, crítica e criatividade, estando esta muito aquém do preconizado pelos Parâmetros Curriculares Nacionais.

No ensino superior, é desejável que o estudante domine a compreensão em leitura e demonstre articulação, fluência e análise crítica e criativa das informações (Cunha \& Santos, 2006). Investigações em âmbito nacional (Santos, 1997; Santos, Primi, Taxa, \& Vendramini, 2002; Oliveira, 2007; Oliveira, Santos, \& Primi, 2003; Oliveira, Suehiro, \& 
A leitura proficiente não é tarefa simples. Autores como Carpenter, Miyake e Just (1995), Hannon e Daneman (2001) e Kintsch e van Dijk (1978) concordam que a leitura exige processamentos como memória, consciência fonológica, domínio sintático e semântico das palavras, pensamento analógico, fluência e velocidade.
Santos, 2004; Oliveira \& Santos, 2005, 2006, 2008; Sampaio \& Santos, 2002; Silva \& Witter, 2009; Suehiro, Santos, \& Oliveira, 2004, entre outras) revelaram que os estudantes que chegam ao ensino superior apresentam uma fraca compreensão em leitura. A falta de proficiência nessa capacidade pode produzir uma formação deficitária, haja vista que o estudante terá dificuldade para a compreensão das informações dos conteúdos técnicos inerentes à sua formação.

A leitura proficiente não é tarefa simples. Autores como Carpenter, Miyake e Just (1995), Hannon e Daneman (2001) e Kintsch e van Dijk (1978) concordam que a leitura exige processamentos como memória, consciência fonológica, domínio sintático e semântico das palavras, pensamento analógico, fluência e velocidade. Flippo (1998) afirma que a compreensão em leitura se concretiza diante de um processamento verbal que envolve a relação entre as decodificações de sinais entre estímulos e os conhecimentos prévios dos alunos.

Desse modo, conhecimentos previamente armazenados podem ser facilitadores da compreensão em leitura, especialmente aqueles adquiridos em razão da formação acadêmica (Kintsch, 1988; Mcnamara, Sternberg, \& Hardy, 1991; Taylor, 1992). Todavia, argumenta-se que, se a compreensão está relacionada aos conhecimentos preexistentes e se também é fato que a falta de compreensão textual vem ocorrendo desde as séries iniciais da educação formal (Gomes \& Boruchovitch, 2005; Joly \& Nicolau, 2005; Oliveira et al., 2009; Santos, Rueda, \& Bartolomeu, 2006, entre outros), então é possível que, ao chegar ao ensino superior, o estudante apresente um repertório de conhecimentos pouco diversificado, o que poderia invariavelmente contribuir de forma negativa para a realização de uma leitura com compreensão.
Outro aspecto relevante quanto à proficiência em leitura de estudantes universitários se refere ao conhecimento sobre compreensão e ao conhecimento de como compreender (Nicholson, 1999). O primeiro, denominado metacompreensão, refere-se à habilidade para refletir acerca do próprio processamento, permitindo a percepção de quando não foi possível compreender. O segundo diz respeito à habilidade de regular o próprio pensamento durante a leitura, de criar analogias e fazer críticas ao conteúdo lido; essa habilidade é conhecida como metacognição (Nicholson, 1999). Simonsen e Singer (1992), Dembo (1994) e Maki, Shields, Wheeler e Zacchilli (2005) sustentam que o processo de compreensão implica a elaboração mental da informação lida. Destaca-se, então, o papel da metacognição, que cuida do monitoramento e da regulação do comportamento.

Muitos estudantes não conseguem estabelecer analogias, elaborar críticas ou ainda monitorar a própria compreensão, pois também lhes falta diversificação dos conhecimentos prévios, e, somado a isso, estão às dificuldades inerentes às falhas de uma formação deficiente que denotam pouco domínio sintático e semântico. Os estudantes, de um modo geral, não apresentam plena consciência e monitoramento do próprio processo de compreensão em leitura. Não há autocontrole do processo de compreensão, e os alunos não são capazes de identificar se conseguiram ou não compreender a informação lida, portanto, não regulam o comportamento de modo a otimizar sua leitura (Mokhtari \& Reichard, 2002).

Face às considerações apresentadas, constatase que a compreensão em leitura, por se tratar de uma tarefa complexa, é difícil de ser mensurada. Um recurso empregado como medida de compreensão em leitura é a técnica de Cloze (Taylor, 1953), que, em sua versão tradicional, consiste em um texto 
de 250 palavras, no qual se omitem todos os quintos vocábulos, e, no local, coloca-se um traço de tamanho proporcional ao da palavra omitida. Em um texto preparado de acordo com a técnica de Cloze, há a necessidade de se manter intactos o primeiro e o último parágrafos. O teste de Cloze, diferentemente de outros testes diagnósticos que requerem inferência de significado na análise estrutural do texto ou do contexto, enfatiza o papel do leitor no processo de compreensão, pois admite que há interação entre o leitor e o texto.

Cunha (2009) e Oliveira e Santos (no prelo) observam que o Teste de Cloze apresenta evidência de sua validade como medida de compreensão em leitura. Trata-se de um recurso simples de ser utilizado, sendo que, no período de 1976 a 2007, Cunha levantou 52 pesquisas nacionais que utilizaram a técnica de Cloze, e, do ano 2000 até os dias atuais, houve um aumento no emprego do Cloze nas investigações científicas.

Quanto à correção do Cloze, esta se baseia em três critérios, a saber: literal, sinônima e ponderada, conforme descrito por Oliveira, Boruchovitch e Santos (2007, 2009). Na correção literal, considera-se como acerto o preenchimento correto (grafia) da palavra exata que foi omitida, atribuindo-se um ponto para o acerto e zero para o erro. Já a correção sinônima admite como acerto o preenchimento de uma palavra com sentido sinônimo da palavra omitida. Por fim, na correção ponderada, não se leva em consideração se, ao preencher a palavra exata que foi omitida, o aluno cometer algum erro gramatical, respeitando somente o critério de que a palavra deve apresentar um sentido adequado ao contexto.

Bormuth (1968) aponta parâmetros de interpretação do número de pontos obtidos no Cloze. O autor considera que o leitor que não consegue abstrair de forma satisfatória a informação lida (pontuação de até 44\% de acertos) pode ser classificado no nível frustração de leitura. Já aquele que possui uma compreensão apenas suficiente para o entendimento (de $44,1 \%$ a $57 \%$ de acertos) pode ser classificado no nível instrucional. Por último, o leitor que demonstra uma compreensão crítica, criativa, autônoma e fluente do texto (superior a $57 \%$ de acertos) deve ser classificado no nível independente. Alguns estudos realizados com o Teste de Cloze (Santos et al., 2002; Oliveira \& Santos, 2008; Oliveira et al., 2007; Oliveira e Santos, no prelo, entre outros) evidenciaram que os estudantes universitários apresentam uma compreensão em leitura classificada no nível instrucional. Essas investigações revelaram também que, no Teste de Cloze, os itens mais fáceis ao preenchimento, isto é, mais acertados pelos universitários, são as preposições e os artigos, em razão de tais itens não dependerem de maior compreensão do contexto. Os itens considerados de dificuldade média foram aqueles classificados como substantivo, e os itens mais difíceis ao acerto foram classificados como verbo e pronome, sendo que possivelmente esses itens sejam mais acertados por estudantes que possuem um nível independente de leitura. Para autores como Joly (2001) e Gilabert, Martinez e Vidal-Abarca (2005), para que a compreensão crítica e criativa (nível independente) seja atingida pelos estudantes, é necessário um intercâmbio entre o texto e o indivíduo, que, por sua vez, desenvolve seu pensamento reflexivo por meio das relações estabelecidas no meio. Oliveira e Santos (no prelo) indicam que uma leitura bem sucedida é aquela na qual o leitor consegue atribuir significado ao conteúdo lido, lendo em ambientes adequados para essa finalidade. Assim sendo, considerase a universidade como o último campo formal no qual o aprimoramento da leitura se concretiza, especialmente quando esse campo propicia condições (programas interventivos) para que a leitura atinja seu 
nível independente. Sob essa perspectiva, pode-se dizer que o contexto universitário exige bom desempenho na resolução das tarefas acadêmicas e que nem sempre os estudantes conseguem responder de forma satisfatória (Dias \& Vendramini, 2008).

Nesta pesquisa, buscar-se-á explorar a compreensão em leitura de universitários brasileiros. Algumas pesquisas brasileiras apontam que a compreensão em leitura de universitários está aquém do esperado para esse tipo de escolaridade (Cunha \& Santos, 2006; Dias \& Vendramini, 2008; Oliveira \& Santos, 2005, 2006; Oliveira et al., 2003; Pinto, Alvarenga, \& Kock, 1997; Santos, 1997; Santos et al., 2002; Silva \& Witter, 2008, 2009; Suehiro et al., 2004, entre outros). Posto isso, o objetivo da presente investigação será realizar um estudo exploratório e descritivo, tendo por foco descrever a compreensão em leitura de estudantes universitários de diferentes Estados brasileiros, universidades e cursos.

\section{Método}

\section{Participantes}

Participaram da pesquisa 1022 estudantes universitários dos cursos de Administração $(10,6 \%, \underline{n}=108)$, Direito $(7,4 \%, \underline{n}=76)$, Psicologia $(43,2 \%, \underline{n}=441)$, enfermagem $(12,2 \%, \underline{n}=125)$, odontologia $(10 \%, n=102)$, educação física $(4,6 \%, \underline{n}=47)$ e Matemática $(12 \%, \underline{n}=123)$ de universidades privadas e públicas dos Estados de São Paulo, Minas Gerais e Paraná. A média de idade foi de 23 anos e 4 meses $(\underline{D p}=5,8)$. A idade mínima foi de 17 anos, e a máxima, de 53. O gênero masculino representou $29,3 \%(\underline{n}=299)$ da amostra, e o feminino, $70,5 \%(\underline{n}=721)$; apenas duas pessoas $(0,2 \%)$ não informaram o gênero. Cabe mencionar que a amostra foi estabelecida por conveniência.

\section{Instrumentos}

A compreensão da leitura foi avaliada pelo Teste de Cloze. A técnica foi criada em 1953, quando Wilson Taylor iniciou investigações que versavam sobre a elaboração de uma técnica confiável para avaliar a compreensão de textos. Para utilizar a técnica, é necessário selecionar um texto de aproximadamente 250 a 300 palavras que representam um assunto determinado, e nele devem-se omitir todas as quintas palavras do texto; no local da lacuna, deve-se colocar um traço de tamanho proporcional ao do vocábulo excluído. Bormuth (1968) salienta que a utilização de textos com 250 palavras apresentou um coeficiente de 0,85 de confiabilidade da compreensão de texto. Neste estudo, utilizouse um texto de 250 palavras adaptado de Veríssimo (1995), intitulado Desentendimento, em que foram feitas 46 omissões. O critério de correção foi o literal, que considera como acerto o preenchimento da palavra exata que foi omitida, sendo que a pontuação no Cloze poderia variar de 0 a 46, considerando 0 para os erros e 1 para os acertos. O Teste de Cloze utilizado na presente pesquisa apresenta evidências de validade de construto aferida por meio da teoria da resposta ao item (Oliveira \& Santos, no prelo). No estudo realizado com o mesmo texto utilizando a TRI, foi possível evidenciar que o texto apresentou um bom ajuste ao modelo Rash, bem como que os itens foram respondidos conforme o padrão esperado, o que demonstrou um bom ajuste.

\section{Procedimento}

Um bom rapport foi realizado antes da aplicação coletiva do Teste de Cloze em sala de aula com os estudantes que consentiram em participar, por meio da assinatura do Termo de Consentimento Livre e Esclarecido. Os aplicadores, em um total de sete, foram professores do curso de Psicologia que ministraram disciplinas relacionadas à 
avaliação psicológica e que atuavam nas universidades pesquisadas. Todos os aplicadores receberam a mesma instrução de como proceder. As instruções para os alunos foram passadas de forma clara, e, em linhas gerais, como se segue: "será apresentado um texto de aproximadamente 250 palavras, sendo que algumas palavras foram omitidas. Leia todo o texto, em seguida volte completando as lacunas com as palavras que você acredita serem adequadas ao contexto". O tempo aproximado de aplicação foi de 30 minutos, tendo sido observados todos os procedimentos éticos, conforme preconiza a Resolução no 196/96, do Conselho Nacional de Saúde e seus complementares.

\section{Resultados}

Os dados foram organizados em planilha e submetidos à estatística descritiva, visando a atender os objetivos da presente pesquisa. Cabe esclarecer que o objetivo não foi comparar universidades públicas ou privadas, tampouco comparar instituições de ensino superior de diferentes Estados, mas sim, fazer um estudo exploratório e descritivo acerca da compreensão em leitura de estudantes universitários brasileiros. Para tanto, uma análise descritiva das pontuações obtidas mostrou que a média de pontos foi de 19,3 ( $D P=4,8)$. A Figura 1 apresenta a distribuição dos pontos obtidos pelos participantes.

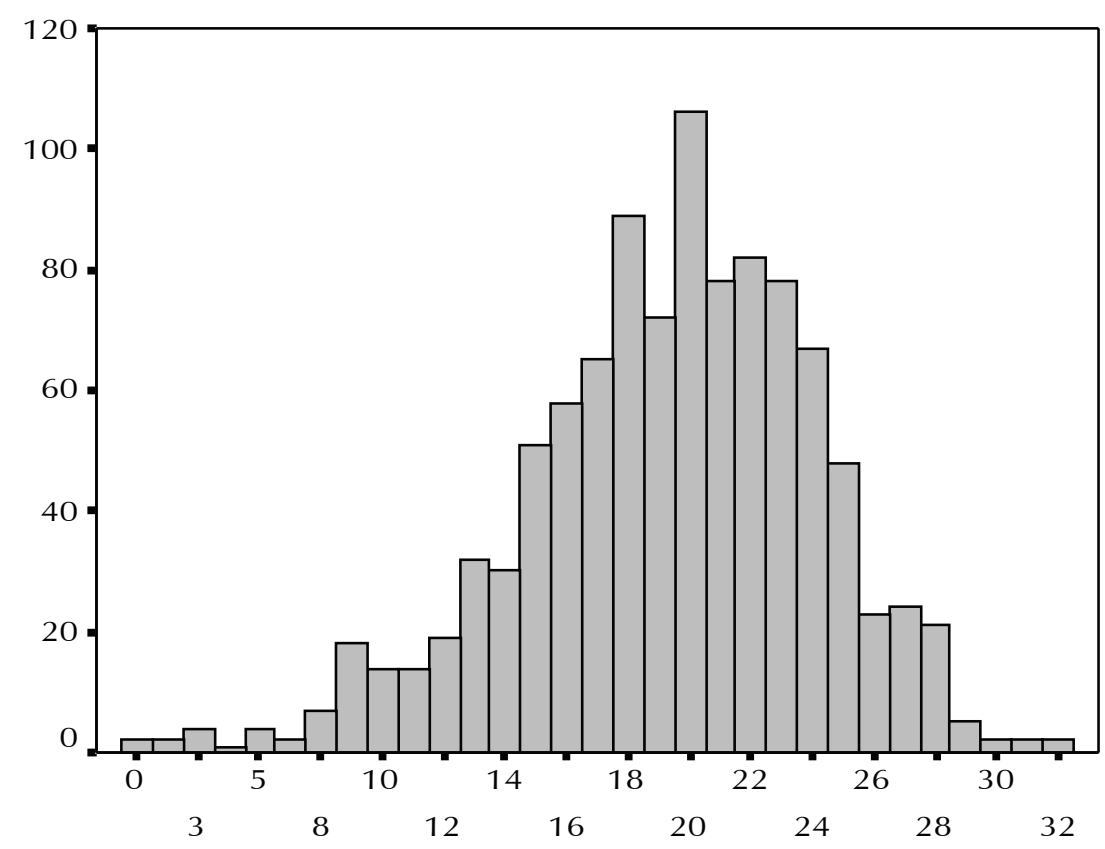

Figura 1. Distribuição das pontuações dos participantes (eixo vertical) no Teste de Cloze (eixo horizontal)

A média de pontos da compreensão em leitura foi baixa, sendo a pontuação mínima de 0 e a máxima, de 32. A distribuição dos dados mostra que a maior parte dos estudantes não conseguiu atingir sequer a metade de acertos possíveis no teste (23 pontos).

Também foi realizada uma análise qualitativa dos acertos dos estudantes, a fim de compreender de forma mais qualitativa quais palavras e respectivas categorias morfo-sintáticas seriam mais fáceis aos participantes. Para tanto, os itens passaram por uma avaliação na qual juízes especialistas da 
área, isto é, Doutores em Linguística, fizeram a análise dos itens do Cloze e aferiram a classificação da dificuldade do item. O Teste de Cloze estudado já havia passado anteriormente por uma análise dos itens feita por cinco juízes (especialistas na área, todos Doutores linguistas), e havia atingido uma concordância de $80 \%$ a $100 \%$ na dificuldade de completar corretamente o item. Basicamente, o juiz, ao fazer uma leitura contextual e analisar a palavra omitida, julgava qual era o grau de dificuldade (fácil, média dificuldade, difícil) de se completar corretamente a palavra na lacuna. Com isso, aferiu-se a validade de conteúdo do instrumento. No presente estudo, o instrumento foi novamente submetido a mais dois juízes que também realizaram um julgamento da dificuldade dos itens, sendo que essa avaliação também ficou dentro do padrão esperado (de $80 \%$ a $100 \%)$.

Com as análises qualitativas dos itens realizadas, foi levantado o número de estudantes que havia acertado cada item. Desse modo, a Tabela 1 apresenta a classificação morfo-sintática, o nível de dificuldade de cada item e o número de estudantes que acertou cada item.

Tabela 1. Frequência e porcentagem de acertos, considerando a dificuldade do item

\begin{tabular}{|c|c|c|c|c|c|}
\hline Item & Palavra & Classificação morfo-sintática & $\begin{array}{l}\text { Dificul- } \\
\text { dade do } \\
\text { item }\end{array}$ & $\begin{array}{l}n \text { de estu- } \\
\text { dantes que } \\
\text { acertaram } \\
\text { o item }\end{array}$ & $\begin{array}{l}\text { \% de estu- } \\
\text { dantes que } \\
\text { acertaram } \\
\text { o item }\end{array}$ \\
\hline 6 & garçom & Substantivo masculino singular & $\mathrm{D}$ & 143 & 14,0 \\
\hline 7 & silêncio & Substantivo masculino singular & $\mathrm{D}$ & 8 & 0,8 \\
\hline 18 & polar & Adjetivo & $\mathrm{D}$ & 23 & 2,3 \\
\hline 31 & afastada & Adjetivo & $\mathrm{D}$ & 14 & 1,4 \\
\hline 36 & morno & Adjetivo & $\mathrm{D}$ & 56 & 5,5 \\
\hline 1 & vez & Substantivo feminino singular & $\mathrm{F}$ & 871 & 85,2 \\
\hline 2 & $\mathrm{a}$ & $\begin{array}{l}\text { Preposição (pois está antes do verbo; } \\
\text { artigo, antes de substantivo) }\end{array}$ & $\mathrm{F}$ & 670 & 65,3 \\
\hline 3 & hotel & Substantivo masculino singular & $\mathrm{F}$ & 496 & 48,5 \\
\hline 5 & coisa & Substantivo feminino singular & $\mathrm{F}$ & 508 & 49,7 \\
\hline 8 & de & Preposição & $\mathrm{F}$ & 902 & 88,3 \\
\hline 9 & finalmente & Advérbio & $\mathrm{F}$ & 74 & 7,2 \\
\hline 10 & $\mathrm{a}$ & Artigo definido feminino singular & $\mathrm{F}$ & 853 & 83,5 \\
\hline 11 & leite & Substantivo masculino singular & $\mathrm{F}$ & 836 & 81,8 \\
\hline 15 & uma & Artigo indefinido feminino singular & $\mathrm{F}$ & 564 & 55,2 \\
\hline 17 & de & Preposição & $\mathrm{F}$ & 850 & 83,2 \\
\hline 19 & ele & $\begin{array}{l}\text { Pronome pessoal do caso reto, } \\
3 \text { a. pessoa do singular }\end{array}$ & $\mathrm{F}$ & 553 & 58,0 \\
\hline 20 & $\mathrm{e}$ & Conjunção & $\mathrm{F}$ & 759 & 74,3 \\
\hline 21 & com & Preposição & $\mathrm{F}$ & 735 & 71,9 \\
\hline 22 & do & $\begin{array}{l}\text { Contração da preposição de mais o } \\
\text { artigo definido masculino singular o }\end{array}$ & $\mathrm{F}$ & 893 & 87,4 \\
\hline 24 & mesa & Substantivo feminino singular & $\mathrm{F}$ & 732 & 71,6 \\
\hline 25 & para & Preposição & $\mathrm{F}$ & 860 & 84,1 \\
\hline 26 & para & Preposição & $\mathrm{F}$ & 886 & 86,7 \\
\hline 28 & garçom & Substantivo masculino singular & $\mathrm{F}$ & 742 & 72,6 \\
\hline
\end{tabular}


Continuação Tabela 1

Dificul- $\quad n$ de estu- $\%$ de estu-

dade do dantes que dantes que

Item Palavra Classificação morfo-sintática

item acertaram acertaram

o item o item

\begin{tabular}{|c|c|c|c|c|c|}
\hline 29 & com & Preposição & $\mathrm{F}$ & 718 & 70,3 \\
\hline 30 & depois & Advérbio & $\mathrm{F}$ & 436 & 42,7 \\
\hline 33 & OS & Artigo definido masculino plural & $\mathrm{F}$ & 793 & 77,6 \\
\hline 34 & na & $\begin{array}{l}\text { Contração da preposição em mais o } \\
\text { artigo definido feminino singular a }\end{array}$ & $\mathrm{F}$ & 145 & 14,2 \\
\hline 35 & brinde & Substantivo masculino singular & $\mathrm{F}$ & 21 & 2,1 \\
\hline 39 & mais & Adjetivo & $\mathrm{F}$ & 182 & 17,8 \\
\hline 41 & também & Advérbio & $\mathrm{F}$ & 81 & 7,9 \\
\hline 42 & frita & Adjetivo & $\mathrm{F}$ & 781 & 76,4 \\
\hline 43 & restaurante & Substantivo masculino singular & $\mathrm{F}$ & 814 & 79,6 \\
\hline 44 & era & $\begin{array}{l}\text { Verbo ser - pretérito imperfeito } \\
\text { do indicativo, } 3^{a} \text {. pessoa do singular }\end{array}$ & $\mathrm{F}$ & 652 & 63,8 \\
\hline 45 & e & Conjunção & $\mathrm{F}$ & 267 & 26,1 \\
\hline 4 & japonesa & Adjetivo feminino singular & M & 87 & 8,5 \\
\hline 12 & mímica & Substantivo feminino singular & M & 8 & 0,8 \\
\hline 13 & $\mathrm{o}$ & $\begin{array}{l}\text { Pronome pessoal complementar } \\
\text { de } 3 \text { a . pessoa do singular: ele (o leite) }\end{array}$ & M & 248 & 24,3 \\
\hline 14 & tenha & 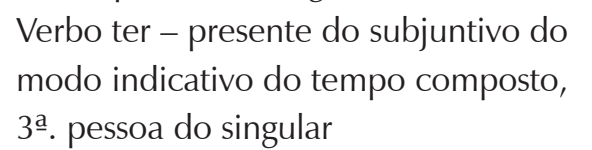 & M & 310 & 30,3 \\
\hline 16 & faria & $\begin{array}{l}\text { Verbo fazer - futuro do pretérito do } \\
\text { modo indicativo, } 3^{\text {a }} \text {. pessoa do singular }\end{array}$ & M & 72 & 7,0 \\
\hline 23 & acompanhava & $\begin{array}{l}\text { Verbo acompanhar - pretérito } \\
\text { imperfeito do modo indicativo, } \\
\text { 3‥ pessoa do singular }\end{array}$ & M & 32 & 3,1 \\
\hline 27 & agradeci & $\begin{array}{l}\text { Verbo agradecer - pretérito perfeito do } \\
\text { modo indicativo, 1… pessoa do singular }\end{array}$ & M & 47 & 4,6 \\
\hline 32 & internacional & Adjetivo & M & 25 & 2,4 \\
\hline 37 & vamos & $\begin{array}{l}\text { Verbo ir - presente simples do modo } \\
\text { indicativo, } 1 \stackrel{\text { a. }}{\text {. pessoa do plural }}\end{array}$ & $M$ & 129 & 12,6 \\
\hline 38 & (de) tradição & Locução adjetiva & M & 7 & 0,7 \\
\hline 40 & contentar & Verbo contentar - infinitivo impessoal & M & 310 & 30,3 \\
\hline 46 & difícil & Adjetivo & M & 449 & 43,9 \\
\hline
\end{tabular}

Na Tabela 1, é possível observar que apenas cinco itens foram considerados difíceis de serem preenchidos corretamente, sendo que a maior parte (29 itens) foi considerada fácil, e o restante (12 itens) foi classificado como itens de média dificuldade de preenchimento. Ao considerar a análise descritiva dos acertos com o julgamento da dificuldade, fica evidente que a maior parte dos acertos apresentou consonância com o julgamento da dificuldade realizada pelos juízes. Nessa direção, os itens considerados mais fáceis foram mais acertados pelos estudantes. 
Os itens foram agrupados por categoria morfo-sintática, e uma nova análise foi realizada. Consideraram-se as categorias sintáticas dos itens e o número possível de opções de respostas em cada um. Dessa forma, o total de sujeitos foi 1022, assim, se o item locução adjetiva fosse acertado por 1022 sujeitos, o total de acertos desse item seria 1022. Os acertos em cada item foram ponderados em termos da frequência e respectiva porcentagem. A Tabela 2 apresenta os dados relativos aos acertos possíveis e aos acertos obtidos.

Tabela 2. Frequência e porcentagem de acertos no Cloze por categoria do item, considerando a dificuldade do item $(\underline{N}=1022)$

\begin{tabular}{|c|c|c|c|c|}
\hline Classificação & Itens & $\begin{array}{l}\text { Acertos } \\
\text { possíveis }\end{array}$ & $\begin{array}{l}\text { Acertos } \\
\text { obtidos }\end{array}$ & $\begin{array}{l}\% \text { por categoria } \\
\text { acertos obtidos }\end{array}$ \\
\hline Locução adjetiva & 38 & 1022 & 7 & 0,7 \\
\hline Advérbios & $9,30,41$ & 3066 & 501 & 16,3 \\
\hline \multirow[t]{2}{*}{ Adjetivos } & \multicolumn{4}{|l|}{$4,18,31,32$} \\
\hline & $36,39,42,46$ & 8176 & 1617 & 19,8 \\
\hline \multirow[t]{2}{*}{ Verbos } & \multicolumn{4}{|l|}{$14,16,23,27$} \\
\hline & $37,40,44$ & 7154 & 1552 & 21,7 \\
\hline Pronomes & 13,19 & 2044 & 801 & 39,2 \\
\hline \multirow[t]{2}{*}{ Substantivos } & \multicolumn{4}{|l|}{$\begin{array}{l}1,3,5,6 \\
7,11,12,24,28\end{array}$} \\
\hline & 35,43 & 11242 & 5179 & 46,0 \\
\hline Artigos & $10,15,33$ & 3066 & 2210 & 72,1 \\
\hline Preposições & $\begin{array}{l}2,8,17,21 \\
22,25,26 \\
29,34\end{array}$ & 9198 & 6659 & 72,4 \\
\hline
\end{tabular}

Observou-se (Tabela 2) que algumas categorias foram menos acertadas do que outras. Desse modo, recorreu-se ao teste $\chi^{\underline{2}}$ para verificar se a distribuição entre as categorias era equitativa. A análise demonstrou diferença estatisticamente significante entre as categorias, considerando $\left[\chi^{2}(7,288,2138)=134,34 ; \underline{p} \leq 0,001\right]$.

\section{Discussão e conclusão}

Os resultados obtidos com a média de pontos obtidos pelos participantes foi muito baixa $(\underline{M}=19,3)$, pois os e studantes não conseguiram atingir nem a metade de acertos possíveis no Cloze (23 pontos). Nenhum participante conseguiu obter 46 pontos. Não se consideram os itens do teste impossíveis de serem respondidos, e, pela razão de nenhum participante ter conseguido obter o total de acertos possíveis, não importando se se tratava de uma universidade pública ou privada, então, pode-se hipotetizar que, independentemente do Estado de proveniência, universidade ou curso, é fato que há uma deficiência na compreensão em leitura dos estudantes universitários brasileiros. Essa média de pontos remete à classificação estabelecida no nível de frustração (Bormuth, 1968), que aparece em estudantes que não apresentam abstração adequada das ideias relevantes do texto. 
Os itens mais acertados na presente pesquisa foram as preposições e os artigos (Tabela 2), considerados mais fáceis possivelmente por terem seu preenchimento associado a palavras contíguas. Esses resultados vão ao encontro de investigações anteriores (Santos et al., 2002; Oliveira \& Santos, 2008; Oliveira et al., 2007; Oliveira \& Santos, no prelo, entre outros) que concluíram que os itens avaliados como fáceis são os mais acertados, pois não dependem de uma habilidade de compreensão em leitura crítica e reflexiva.

De um modo geral, a maior parte da avaliação realizada pelos juízes estava em consonância com os acertos dos estudantes, isto é, itens mais fáceis avaliados pelos juízes também são os mais acertados pelos estudantes. Todavia, conforme se observou na Tabela 1 , ao se comparar os acertos de alguns itens e o julgamento dos juízes, pode-se perceber que alguns itens $(4,9,12,16,23,27,32,35$, $38,41)$ considerados de dificuldade média ou fáceis pelos juízes foram, na verdade, acertados por pouquíssimas pessoas. Esses itens, apesar de serem julgados como passíveis de maior número de acertos, não foram acertados. A hipótese de que a habilidade de compreensão em leitura dos estudantes é deficiente parece plausível diante dos resultados alcançados, e também há que se fomentar a hipótese de que a situação ainda é mais preocupante do que se supunha, pois os juízes julgaram que tais itens, considerando o contexto, seriam fáceis de acertar.

Os resultados alcançados na presente pesquisa, apesar de exploratórios, confirmam as evidências de estudos anteriores (Cunha \& Santos, 2006; Dias \& Vendramini, 2008; Oliveira \& Santos, 2005, 2006; Santos et al., 2002; Silva \& Witter, 2008, 2009; Suehiro et al., 2004, entre outros). Assim sendo, se a compreensão em leitura de nossos futuros profissionais está muito aquém do esperado e se é por meio dela que há o acesso aos conteúdos técnicos científicos, então se questiona a qualidade da formação de nossos estudantes do ensino superior.

\section{Considerações finais}

Este estudo apresentou algumas limitações, dentre as quais se pode citar o fato de ter sido uma amostra predominantemente do curso de Psicologia, o que indica a necessidade de que outros cursos sejam investigados com amostras maiores e mais representativas; também seria relevante investigar possíveis diferenças na compreensão em leitura de estudantes de universidades públicas e privadas. Diante dos resultados levantados na presente pesquisa, não se descarta a necessidade de estudos futuros, haja vista as limitações da presente investigação, que, em sua essência, teve um caráter exploratório.

Há que se considerar que a implementação de programas interventivos demandaria tempo e investimento financeiro das instituições, sejam públicas, sejam privadas. Portanto, as discussões acerca da necessidade desses programas ainda ficam em uma esfera na qual permeia o que é desejável e o de fato ocorre no ensino superior. Ainda que essa realidade pareça distante, espaços de discussão sobre o assunto, como é o caso do presente estudo, devem ser oportunizados. 


\section{Referências}

Bormuth, J. R. (1968). Cloze test readability: Criterion reference scores. Journal of Educational Measurement, 5, 189-196.

Carpenter, P. A., Miyake, A., \& Just, M. A. (1995). Language comprehension: Sentence and discourse processing. Annual Reviews Psychology, 46, 91-120.

Conselho Nacional de Saúde. Resolução no 196/96. Diretrizes e Normas Regulamentadoras de Pesquisa. Recuperado em 19 de outubro de 2005 de http://www.conselho.saude.gov.br.

Cunha, N. B., \& Santos, A. A. A. (2006). Relação entre a compreensão da leitura e a produção escrita em universitários. Psicologia: Reflexão e Crítica, 19(2), 237-245.

Cunha, N. B. (2009). Pesquisas com o teste de Cloze no Brasil. In A. A. A. Santos, E. Boruchovitch, \& K. L. Oliveira (Orgs.), Cloze: um instrumento de diagnóstico e intervenção (pp. 79117). São Paulo: Casa do Psicólogo.

Dembo, M. H. (1994). Applying educational psychology (5th ed.). New York: Longman Publishing Group.

Dias, A. S., \& Vendramini, C. M. M. (2008). Análise fatorial com informação completa de uma prova de compreensão em leitura em estatística. Psicologia Escolar e Educacional, $12(2), 357-367$

Flippo, R. F. (1998). Points of agreement: A display of professional unity in our field. The Reading Teacher, 52, 30-40.

Gilabert, R., Martínez, G., \& Vidal-Abarca, E. (2005). Some good texts are always better. Text revision to foster inferences of readers with high and low prior background knowledge. Learning and Instruction, (15), 45-68.

Gomes, M. A. M., \& Boruchovitch, E. (2005). Desempenho no jogo, estratégias de aprendizagem e compreensão em leitura. Psicologia: Teoria e Pesquisa, 21(3), 319-326.

Hannon, B., \& Daneman, M. (2001). A new tool for measuring and understanding individual differences in the component processes of reading comprehension. Journal of Educational Psychology, 93(1), 103-128.

Instituto Nacional de Estudos e Pesquisas Educacionais Anísio Teixeira - INEP. (2004). Qualidade na educação do ensino médio. Recuperado em 15 de janeiro de 2008 de http://www. inep.gov.br/download/saeb/2004/boletim

Joly, M. C. R. A. (2001). Leitura no contexto educacional: avaliando estratégias para aquisição de habilidades criativas. In F. F. Sisto, E. T. B. Sbardelini, \& R. Primi (Orgs.), Contextos e questões da avaliação psicológica (pp. 98-116). São Paulo: Casa do Psicólogo.

Joly, M. C. R. A., \& Nicolau, A. F. (2005). Avaliação de compreensão em leitura usando Cloze na $4 \stackrel{\text { a }}{\text { série. Temas }}$ sobre desenvolvimento, 14, 14-19.

Joly, M. C. A., Santos, L. M., \& Marini, J. A. S. (2006). Uso de estratégias de leitura por alunos do ensino médio. Paidéia, 16(34), 205-212.

Kintsch, W., \& van Dijk, T. A. (1978). Toward a model of text comprehension and production. Psychological Review, 85 (5), 363-394 
Kintsch, W. (1988). The role of knowledge in discourse comprehension a construction - integration model. Psychological Review, 95(2), 163-182.

McNamara, T. P., Sternberg, R. J., \& Hardy, J. K. (1991). Processing verbal relations. Intelligence, 13, 193-221.

Maki, R. H., Schields, M., Wheeler, A. E., \& Zacchini, T. L. (2005). Individual differences in absolute and relative metacomprehension accurancy. Journal of Educational Psychology, 97(4), 723-731.

Ministério da Educação e Cultura - MEC. (1997). Parâmetros Curriculares Nacionais: Ensino de primeira a quarta séries Recuperado em 10 de janeiro de 2008 de http://portal.mec. gov.br/seb/arquivos

Ministério da Educação e Cultura - MEC. (1998). Parâmetros Curriculares Nacionais: Língua portuguesa: Ensino de quinta a oitava séries. Recuperado em 10 de janeiro de 2008 de http://portal.mec.gov.br/seb/arquivos

Mokhtari, K., \& Reichard, C. A. (2002). Assessing students' metacognitive awareness of reading strategies. Journal of Educational Psychology, 94(2), 249-259.

Nicholson, T. (1999). Reading comprehension processes. In G. B. Thompson, \& T. Nicholson (Orgs.), Learning to read (pp. 127-149). Newark: IRA.

Oliveira, K. L. (2008). Compreensão da leitura, atitudes de leitura e desesperança em universitários. Psicologia: Ciência e Profissão, 28(4), 820-831.

Oliveira, K. L., Boruchovitch, E., \& Santos, A. A. A. (2007). Compreensão de leitura em alunos de sétima e oitava séries do ensino fundamental. Psicologia Escolar e Educacional, 11(1), 41-49.

Oliveira, K. L., Boruchotvitch, E., \& Santos, A. A. A. (2008). Leitura e desempenho escolar em português e matemática no ensino fundamental. Paidéia, 18(41), 531-540.

Oliveira, K. L., Boruchotvitch, E., \& Santos, A. A. A. (2009). A técnica de Cloze na avaliação da compreensão em leitura. In A. A. A. Santos, E. Boruchovitch, \& K. L. Oliveira (Orgs.), Cloze: um instrumento de diagnóstico e intervenção (pp. 4770.). São Paulo: Casa do Psicólogo.

Oliveira, K. L., Boruchotvitch, E., \& Santos, A. A. A. (2009). Leitura e desempenho escolar em alunos do ensino fundamental. In A. A. A. Santos, E. Boruchovitch, \& K. L. Oliveira (Orgs.), Cloze: um instrumento de diagnóstico e intervenção (pp.149-164). São Paulo: Casa do Psicólogo.

Oliveira, K. L., Cantalice, L. M., \& Freitas, F. A. (2009). Compreensão em leitura no ensino médio: análise de acertos por item. In A. A. A. Santos, E. Boruchovitch, \& K. L. Oliveira (Orgs.), Cloze: um instrumento de diagnóstico e intervenção (pp.165-185). São Paulo: Casa do Psicólogo.

Oliveira, K. L., Santos, A. A. A., \& Primi, R. (2003). Estudo das relações entre compreensão em leitura e desempenho em disciplinas na universidade. Revista Interação em Psicologia, 7(1), 19-25

Oliveira, K. L., \& Santos, A. A. A. (2005). Compreensão em leitura e avaliação da aprendizagem em universitários. Psicologia: Reflexão e Crítica, 18(1), 118-124.

Oliveira, K. L., \& Santos, A. A. A. (2006). Compreensão de textos e desempenho acadêmico. Psic - Revista de Psicologia da Vetor Editora, 7(1), 19-27.
Oliveira, K. L., \& Santos, A. A. A. (2008). Estudo de intervenção para a compreensão da leitura e produção de textos na universidade. Interação, 12(2), 169-177.

Oliveira, K. L., \& Santos, A. A. A. (no prelo). Ajustamento de um teste de Cloze ao modelo Rasch: análise do funcionamento diferencial do item. Manuscrito submetido a publicação na Psicologia: Teoria e Pesquisa

Oliveira, K. L., Suehiro, A. C. B., \& Santos, A. A. A. (2004). Avaliação da aprendizagem no ensino superior: estudo da relação com a compreensão em leitura. In C. Machado, L. S. Almeida, M. Gonçalves, \& V. Ramalho (Orgs.), Avaliação psicológica: formas e contextos (pp.217-223). Braga: Psiquilíbrios Edições.

Pinto, C. J. A., Alvarenga, M. A. P., \& Kock, R. A. A. (1997). Hábitos de leitura e compreensão de texto entre universitários. In G. P. Witter (Org.), Leitura e universidade (pp.133-165). Campinas, SP: Alínea.

Sampaio, I. S., \& Santos, A. A. A. (2002). Leitura e redação entre universitários: avaliação de um programa de intervenção. Psicologia em Estudo, 7(1), 31-38.

Santos, A. A. A. (1997). Psicopedagogia no 3o grau: avaliação de um programa de remediação em leitura e estudo. ProPosições, 8(1), 27-37.

Santos, A. A. A., Primi, R., Taxa, F., \& Vendramini, C. M. M. (2002). O teste de Cloze na avaliação da compreensão em leitura. Psicologia: Reflexão e Crítica, 15(3), 549-560.

Santos, A. A. A., Rueda, F. J. M., \& Bartolomeu, D. (2006). Avaliação dos aspectos afetivos envolvidos nas dificuldades de aprendizagem. In F. F. Sisto, \& S. C. Martinelli (Orgs.), Afetividade e dificuldades de aprendizagem (pp.93-110). São Paulo: Vetor.

Silva, E. M. T., \& Witter, G. P. (2008). Compreensão de texto e desempenho acadêmico em estudantes de psicologia. Estudos de Psicologia, 25(3), 395-403.

Silva, E. M. T., \& Witter, G. P. (2009). Eficiência de um curso de português no desenvolvimento da leitura e escrita. In A. A. A. Santos, E. Boruchovitch, \& Oliveira, K. L. (Orgs.), Cloze: um instrumento de diagnóstico e intervenção (pp. 311-342). São Paulo: Casa do Psicólogo.

Simonsen, S., \& Singer, H. (1992). Improving reading instruction in the content áreas. In S. J. Samuels, \& A. E. Farstrup (Eds.), What research has to say about reading instruction (pp. 200219). Newark: IRA.

Suehiro, A. C. B., Santos, A. A. A., \& Oliveira, K. L. (2004). Habilidades em compreensão da leitura: um estudo com alunos de psicologia. Estudos de Psicologia, 21(2), 29-41.

Taylor, B. M. (1992). Text structure, comprehension and recall. In S. J. Samuels, \& A. E. Farstrup (Eds.), What research has to say about reading instruction (pp. 220-235). Newark: IRA

Taylor, W. L. (1953). Cloze procedure: A new tool for measuring read-ability. Journalism Quarterly, 30, 415-433.

Veríssimo, L. F. (1995). Desentendimento. Ícaro - revista de bordo da Varig, XII(136), 11. 